\title{
RANCANGAN INSTALASI PENGOLAHAN AIR LIMBAH PADA PROSES PRODUKSI UKM BATIK DI KABUPATEN SIDOARJO
}

\author{
Ong Andre Wahyu Riyanto ${ }^{1}$, Siswadi $^{2}$, Fitra Mardiana ${ }^{3}$, Moch. Rizal Fadli ${ }^{4}$ \\ ${ }^{1}$ Universitas Wijaya Putra \\ ${ }^{2}$ Universitas Wijaya Putra \\ ${ }^{3}$ Universitas Wijaya Putra \\ ${ }^{4}$ Universitas Wijaya Putra \\ ongandre@uwp.ac.id
}

\begin{abstract}
Abstrak
Sentra UKM Batik Jetis merupakan UKM penghasil kain batik yang terletak di wilayah Sidoarjo, Jawa Timur. Jenis batik yang diproduksi adalah batik tulis dan batik cap. Seiring dengan peningkatan produktivitas, ternyata timbul permasalahan pada lingkungan. Hasil sampingan proses produksi batik berupa limbah cair telah membebani lingkungan sekitar lokasi UKM. Permasalahan ini juga kerap kali diabaikan oleh pihak pengrajin, padahal saat ini permasalahan lingkungan menjadi isu yang penting. Hal ini mengartikan bahwa proses produksi batik di sentra UKM batik Jetis di kabupaten Sidoarjo meskipun secara bisnis memiliki keuntungan yang terjangkau tetapi memiliki proses produksi yang tidak berkelanjutan terhadap lingkungan. Oleh karena itu diperlukan intervensi untuk mengurangi pencemaran lingkungan dengan memperhatikan pembuangan limbah cair yang sesuai dengan baku mutu limbah cair yang berlaku. Metode untuk mengurangi kadar limbah cair tersebut adalah penerapan instalasi pengolahan air limbah (IPAL) dengan teknologi tepat guna eletrokoagulan yang sesuai dengan kebutuhan UKM. Hasil penerapan rancangan tekonologi tepat guna tersebut diharapkan UKM Batik Jetis Sidoarjo dapat menjadi sentra UKM batik yang memiliki proses produksi yang berkelanjutan terhadap lingkungan sekaligus secara bisnis memiliki keuntungan yang terjangkau.
\end{abstract}

Kata Kunci : batik, UKM, IPAL, teknologi tepat guna, limbah cair

\section{PENDAHULUAN}

Sentra UKM Batik Jetis adalah UKM kerajinan kain batik di Kabupaten Sidoarjo, Jawa Timur. Jenis batik yang diproduksi adalah batik tulis dan batik cap. Output produksi UKM selama satu tahun produksi dihitung berdasarkan perkiraan masing-masing UKM. UKM pertama menyatakan bahwa output produksi sebanyak 241.944 meter dalam satu tahun proses produksi. Sedangkan UKM kedua menyatakan bahwa output produksi rata-rata 108.000 meter dalam satu tahun produksi. UKM ketiga memperkirakan bahwa output produksi sebanyak 19.200 meter selama satu tahun produksi.

Proses produksi pada UKM tersebut juga menghasilkan hasil sampingan berupa limbah buangan (waste) baik berupa limbah padat maupun limbah cair. Limbah padat berupa sisa-sisa lilin/malam hasil pencucian dan pelorodan kain batik diolah kembali menjadi lilin/malam untuk dapat dipergunakan lagi dalam pembatikan. Sedangkan untuk limbah cair langsung di buang ke saluran selokan yang mengalir menuju ke sungai.

Teknologi Tepat Guna 169 
Limbah cair dari proses pembatikan jumlahnya cukup banyak dan mayoritas berasal dari air proses pencucian, perendaman, pelorodan dan pencelupan warna. Limbah cair tersebut mengandung kadar Chemical Oxygen Demand (COD) dan Biological Oxygen Demand (BOD) yang tinggi. Dampak tingginya kadar COD dan BOD dari limbah cair tersebut dapat menyebabkan bau yang menyengat dan polusi pada air yang dapat membahayakan ekosistem lingkungan (manusia, hewan dan tumbuhan).

Oleh karena itu, sangat penting bagi UKM batik untuk memperhatikan aspek-aspek lingkungan dalam proses produksinya agar dapat menciptakan keserasian dengan lingkungan sekitarnya. Kadar BOD dan COD pada proses produksi perlu dikurangi sampai pada batas kadar COD dan BOD yang diijinkan oleh peraturan pemerintah daerah Jawa Timur.

Tujuan dari kegiatan ini adalah membantu UKM untuk menemukan cara yang efektif dan efesien untuk mengurangi kadar limbah cair yang dihasilkan pada proses produksi batik. Rekomendasi kepada UKM batik Jetis Kabupaten Sidoarjo adalah menerapkan suatu teknologi instalasi pengolahan air limbah yang dapat digunakan untuk mengurangi kadar Chemical Oxygen Demand (COD) dan Biological Oxygen Demand (BOD) pada ambang batas yang masih diijinkan oleh pemerintah daerah. Selain itu, teknologi ini juga diharapkan mudah dioperasikan oleh pihak UKM batik.

\section{METODE}

Pengabdian masyarakat dilakukan di Desa Jetis Kabupaten Sidoarjo, karena pada UKM batik di desa tersebut belum mengelola air limbah produksi batik. Air limbah tersebut langsung dibuang ke selokan yang mengalir menuju sungai. Kondisi ini menjadi masalah bagi UKM batik dan masyarakat, karena air limbah dapat mengkontaminasi air sumur maupun air sungai di Kelurahan Jetis. Sehingga akan berdampak buruk terhadap kesehatan dan penyakit kulit gatal-gatal dan penyakit kulit lainnya.

Solusi yang direkomendasikan terhadap masalah tersebut adalah melalui pendekatan bersama pemerintah Kelurahan Jetis dan UKM batik guna mensinergikan program pemerintah desa dengan masalah penanggulangan pencemaran lingkungan dampak dari limbah cair batik. Terutama rekomendasi ini diperuntukkan bagi UKM pengrajin batik yang belum memiliki fasilitas pengolahan limbah cair batik di Desa Jetis.

Fasilitas pengolahan air limbah yang direkomendasikan adalah menggunakan metode elektro koagulan yang dapat difungsikan untuk digunakan oleh UKM pengrajin secara bersamasama.

Fasilitas instalasi pengolahan air limbah ini dapat mengolah limbah cair batik dengan efektif, efisien serta mudah dalam operasionalnya. Rancangan fasilitas instalasi pengolahan limbah cair batik ini dapat menjadi alat yang dibangun dan diharapkan akan dapat dipakai sebagai contoh yang dapat diimplementasikan di daerah lain di Indonesia.

Tahapan kegiatan ini diantaranya adalah: 1) melakukan pengamatan secara langsung ke lokasi UKM. 2) Melakukan wawancara dengan pengrajin batik mengenai permasalahan air limbah. 3)Kemudian mengidentifikasi masalahan air limbah pada UKM pengrajin batik. Selanjutnya memformulasikan rancangan instalasi pengolahan air limbah yang akan dibuat sebagai berikut: Pertama, bagaimanakah rancangan instalasi pengolahan limbah cair yang dapat digunakan untuk mengolah limbah cair batik agar hasil pengolahannya sesuai baku mutu limbah cair industri batik yang berlaku. Kedua, bagaimana cara mengedukasi kepada UKM pengrajin batik untuk memahami pentingnya teknologi pengolahan limbah cair batik.

\section{HASIL DAN PEMBAHASAN}

Tahap rancangan instalasi pengolahan limbah cair batik untuk menyelesaikan permasalahan air limbah pada UKM pengrajin batik di Desa Jetis, yaitu agar air limbah sesuai dengan baku mutu limbah cair batik menurut Peraturan Gubernur Jawa Timur Nomor 52 Tahun 2014 Tentang Perubahan Atas Peraturan Gubernur Jawa Timur Nomor 72 Tahun 2013 Tentang Baku Mutu Air Limbah Bagi Industri dan/atau Kegiatan Usaha Lainnya.

$$
\text { Teknologi Tepat Guna }
$$


Tahap rancangan instalasi pengolahan air limbah batik dengan metode elektro koagulan adalah: 1)Bak penampung air limbah terbuat dari plat stainless steel dengan dimensi panjang $1.000 \mathrm{~mm}$, lebar $1.000 \mathrm{~mm}$, dan tinggi $600 \mathrm{~mm}$. Bak penampung air limbah ini berfungsi untuk menampung limbah sebelum dialirkan ke proses koagulasi. 2) Bak elektrokoagulan yang terbuat dari plat stainless steel dengan dimensi panjang $2.000 \mathrm{~mm}$, lebar $500 \mathrm{~mm}$, dan tinggi $600 \mathrm{~mm}$. Di dalam bak elektro koagulan ini ini air limbah akan diproses dalam waktu tertentu untuk terjadinya proses elektro kimia, sehingga nanti akan terbentuk flok-flok. 3) Bak pengendapan yang terbuat dari plat stainless steel. Pada tahapan dalam bak penampungan ini perlu waktu, sehingga dibutuhkan ukuran yang lebih besar. Bak ini terbuat dari pelat satainless steel dengan ukuran dimensi panjang $2.000 \mathrm{~mm}$, lebar $2.000 \mathrm{~mm}$ dan tinggi 1.000 $\mathrm{mm}$. 4) Bak filtrasi terdiri dari 3 bak yang terbuat dari plat stainless steel, setiap bak memiliki ukuran panjang $2.000 \mathrm{~mm}$ lebar $1.000 \mathrm{~mm}$ dan tinggi 1.000 $\mathrm{mm}$. Bak pertama menggunakan media filter koral, bak kedua menggunakan media split, kemudian bak ketiga menggunakan media pasir dan arang aktif. 5) Instalasi elektro koagulan adalah instalasi pengolahan air limbah cair yang dilengkapi rangkaian elektronik yang terdiri dari 20 lempeng katoda-anoda dengan boks travo penyearah untuk merubah arus listrik AC menjadi DC dengan output tegangan 24 Volt dan arus 5 Ampere. 6) Dalam merakit dibutuhkan akurasi dimensi pada proses pembuatan, sehingga akan diperoleh sistem yang efesien baik dalam desain maupun kinerja alat.

7) Uji coba memerlukan pengamatan dan pendataan secara detail, hal ini dimaksudkan untuk mendapatkan informasi sebagai dasar proses perbaikan.

Pengolahan dengan metode elektro koagulasi akan menghasilkan gumpalan padat. Tidak membutuhkan bahan kimia koagulan membuat produk padatan yang relatif lebih kecil.
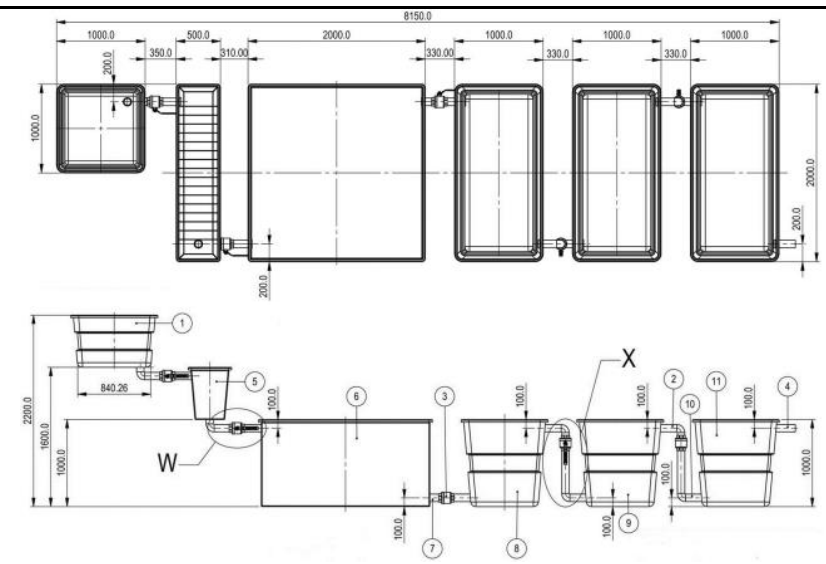

Gambar 1. Desain Teknis Instalasi Pengolahan Air Limbah Pencucian Kain Batik

\section{KESIMPULAN}

Rancangan instalasi pengolahan air limbah batik dengan teknologi elektrokoagulan ini memiliki kapasitas 125 liter/jam. Mampu menghasilkan limbah cair UKM batik pengrajin mitra sesuai dengan baku mutu limbah cair batik menurut Peraturan Gubernur Jawa Timur Nomor 52 Tahun 2014 Tentang Perubahan Atas Peraturan Gubernur Jawa Timur Nomor 72 Tahun 2013 Tentang Baku Mutu Air Limbah Bagi Industri dan/atau Kegiatan Usaha Lainnya. Pembinaan tentang pengolahan limbah cair batik terhadap UKM pengrajin batik sebaiknya dilkasanakan secara berkesinambungan, agar UKM pengrajin batik mampu mengoperasikan dan merawat instalasi pengolahan limbah cair batik tersebut dengan baik.

\section{UCAPAN TERIMAKASIH}

Ucapan terimakasih disampaikan kepada DRPM Kemenristek Dikti yang telah memberikan hibah pendanaan pelaksanaan pengabdian kepada masyarakat pada skim IbM ini. Ucapan terima kasih disampaikan juga kepada Pimpinan Universitas Wijaya Putra serta Ketua LPPM dan staff yang telah memberikan kepercayaan dan waktu kepada kami untuk melaksanakan kegiatan pengabdian kepada masyarakat ini pada tahun 2016. 


\section{REFERENSI}

Felaza, E., \& Priadi, C. R. (2016, January). Implementation of Cleaner Production in a Natural Dye Batik Industry SME: A way to Enhance Biodegradability of Batik Wastewater?. In MATEC Web of Conferences (Vol. 62). EDP Sciences.

Ghazilla, R. A. R., Sakundarini, N., AbdulRashid, S. H., Ayub, N. S., Olugu, E. U., \& Musa, S. N. (2015). Drivers and barriers analysis for green manufacturing practices in Malaysian SMEs: a preliminary findings. Procedia CIRP, 26, 658-663.

Hoffman, A. J. (2000). Competitive environmental strategy: A guide to the changing business landscape. Island press.

Irjayanti, M., \& Azis, A. M. (2012). Barrier factors and potential solutions for Indonesian SMEs. Procedia Economics and Finance, 4, 3-12.

Johansson, G., \& Winroth, M. (2009). Lean vs. Green manufacturing: Similarities and differences. In Proc. of the 16th International Annual EurOMA Conference, Implementation realizing Operations Management knowledge, June (pp. 1417).

Rinawati, D. I., Sari, D. P., WP, S. N., Muljadi, F., \& Lestari, S. P. (2013). PENGELOLAAN PRODUKSI MENGGUNAKAN PENDEKATAN LEAN AND GREEN UNTUK MENUJU INDUSTRI BATIK YANG BERKELANJUTAN (STUDI KASUS DI UKM BATIK PUSPA KENCANA). J@ TI UNDIP: JURNAL TEKNIK INDUSTRI, 8(1), 43-50.

Singgih, L.Moses, Green Productivity: Konsep dan Aplikasinya, 2012.

Subki, N. S., \& Rohasliney, H. (2011). A Preliminary Study on Batik Effluent in Kelantan State: A Water Quality Perspective., International Conference on Chemical, Biological and Environment Science (ICCEBS'2011).

Syahputra, R., \& Soesanti, I. (2016). Application of Green Energy for Batik Production Process. Journal of Theoretical and Applied Information Technology, 91(2), 249.

Susanty, A., Hartini, S., Puspitasari, D., \&
Arsiwi, P. (2015). Measuring Efficiency of Using Resource in the Production Process of Making Stamped-Batik: A DEA Approach. Mediterranean Journal of Social Sciences, 6(5), 318.

Sulaeman. 2006. Kebutuhan Air, Enerji, Zat Warna Dan Zat Pembantu Untuk Pembuatan 1 Meter Kain Batik Dari Mori. Balai Kerajinan dan Batik Yogyakarta.

Sulaeman. 2004. Manfaat Penerapan Produksi bersih pada Industri Batik.Majalah : Mitra Lingkungan. Jakarta. Edisi September 2004.

Susanto, S.K. Sewan. 1980. Seni Kerajinan Batik Indonesia. Balai Penelitian Batik dan Kerajinan. Lembaga Penelitian dan Pendidikan Industri, Departemen Perindustrian R.I. Yogyakarta.

Tambunan, T. (2005). Promoting small and medium enterprises with a clustering approach: A policy experience from Indonesia. Journal of Small Business Management, 43(2), 138-154.

Tambunan, T. (2008). Development of SME in ASEAN with Reference to Indonesia and Thailand. Chulalongkorn Journal of Economics, 20(1), 53-83.

Walker, E. A., Redmond, J., \& Giles, M. (2010). A Proposed Methodology to Promote Adoption of'Green'Production by Small Firms. International Journal of Business Studies, 18(1), 39.

Zhou, M., Pan, Y., Chen, Z., Yang, W., \& Li, B. (2012). Selection and evaluation of green production strategies: analytic and simulation models. Journal of cleaner Production, 26, 9-17. 